\title{
An Empirical Analysis of Psychological Factors Based on EEG Characteristics of Online Shopping Addiction in E-Commerce
}

Jinke Yang, Intellectual Property Institute, Henan University, China

\begin{abstract}
With the popularity of the internet and the in-depth development of e-commerce, online shopping has broken through time, space, and geographical restrictions and has attracted extensive attention from various social groups. Moderate online shopping can not only save time and expenses, but also plays a role of entertainment to a certain extent. However, excessive online shopping will lead to online shopping addiction, resulting in extreme waste of time and money and even disharmony of social functions. Internet shopping addiction is a psychological dependence on online shopping.
\end{abstract}

\section{KEYWORDS}

Brain Wave, E-Commerce, Internet Shopping Addiction

\section{INTRODUCTION}

With the continuous improvement of China's Internet industry environment and the increasing market penetration rate of online shopping, China's consumption situation is experiencing a great change from traditional consumption to online consumption. Online shopping once entered thousands of households. It is cheap, discounted, fast and convenient, and is well received by consumers. With the popularity of the Internet and the in-depth development of e-commerce, online shopping has broken through the characteristics of time, space and geographical restrictions, making it gradually widely accepted by netizens. It has attracted extensive attention from various social groups, and more and more people use online shopping as the main means of shopping (Balasubramanian, 2015). With the accumulation of days and months, the amount of online shopping has increased, and many consumers addicted to online shopping have emerged. Although the current number of views and conversion rate of users are not high, the unit price of customers is high. Compared with traditional consumption forms, online shopping has unique characteristics such as convenience, variety, price advantage, entertainment orientation, etc. (Arens et al., 2016). While online shopping brings convenience to our lives, there are also hidden dangers. The results of EEG data show that in online addicts, the invalid prompts after online shopping-related cues induce higher P1 and P3 amplitudes in the occipital and apical regions than those after neutral cues (Duff et al., 2015). Behind the popularity of online shopping, there are many psychological and life shortcomings such as waste and irrational consumption.

Although China's e-commerce started late, it has a large population base and rapid development, and has formed a certain scale. The Internet not only brought about a huge prosperity of e-commerce, but also created amazing business value. At the same time, people used to go to physical stores for shopping instead of online shopping (Andrason, 2016). You can shop with a click of the mouse, the price is cheaper than the physical store, and online shopping that saves time and money attracts a 
large number of consumers. The online shopping environment is more intricate than the traditional shopping environment. Online shoppers are faced with more explosive product information, a more convenient and fast one-stop shopping experience, and use more fragmented time (Wang \& Tao, 2015). As a growing group, college students have huge consumption potential, and occupy a large proportion of online shopping groups. Online consumers are faced with a more complex decisionmaking environment when conducting online shopping, and their decision-making style is bound to be very different from the traditional shopping situation (Min \& Zhe, 2015; Research on the Impact of Expectation Regret, n.d.; Wang, 2015). Many white-collar online shopping behaviors are mostly for enjoying the shopping process rather than actual needs. Buying behavior can promote brain dopamine secretion and make people feel happy (Wang et al., 2018). Businessmen have done all they can to attract consumers to buy and meet their psychological needs of "leading the process".

On the online shopping platform, consumers can negotiate with merchants through chat software to purchase and further understand the detailed information of commodities. At the same time, most shopping websites have detailed information on orders and logistics tracking information, so that consumers have a full understanding of the real-time information of commodities (Zhao et al., 2017). With the express delivery network extending in all directions, consumers can purchase goods thousands of miles away through online platforms. At the present stage, the rise of sea panning has even opened up the process of globalization of online shopping. Human's psychological activity is an important embodiment of human brain's advanced function, mainly including cognitive, emotional and volitional behavior processes. All human bodies have magical magnetic field effects. When human beings think, their magnetic field effects will act and change accordingly due to different human consciousness. This effect will form a biological current, namely brain waves (Darin-Mattsson et al., 2018). Modern psychological testing technology is a comprehensive interdisciplinary subject that integrates physiology, psychology, electronics, computer technology and other disciplines to reveal the hidden inside of people. Consumers must intervene and prevent from many aspects in order to get rid of such online shopping addiction behaviors, habits and psychological states that affect their health and destroy the happiness of their families (Celeste \& Fritzell, 2018). Based on this, this paper analyzes the basic characteristics of online shopping addiction under the background of the rapid development of the Internet, and explores the psychological factors of online shopping addiction in e-commerce by analyzing the brain wave characteristics of online shopping addicts including college students.

\section{BASIC CHARACTERISTICS OF INTERNET SHOPPING ADDICTION}

\subsection{Formation Mechanism of Internet Shopping Addiction}

\subsubsection{Interpretation of Consumer Planned Behavior Theory}

As the Internet economy has not been fully developed, its huge profit margin attracts unscrupulous merchants to mislead consumers to snap up through various channels in order to obtain excess profits. The application of consumer planned behavior theory in marketing activities needs to further clarify the connotation of consumer planned behavior theory and realize scientific explanation of consumer behavior theory. It is generally believed that the causes of Internet shopping addiction cannot be explained by a single model. These causes intersect, influence and cause each other (Qian, 2016). Due to the complex social environment and the widespread spread of network information, Party organizations are vulnerable to various unhealthy practices, which prevent them from conscientiously performing their duties. In order to change this situation, it is necessary to carry out ideological and political education for the organizers, and to adjust their ideas through actual cases or various political activities. Consumer's general consumption behavior is influenced by many factors. Economists need to combine with the content of consumer's planned behavior theory when studying consumer's purchase behavior. Internet trading is completely different from the traditional way of trading. Due to the virtual nature of the Internet, consumers cannot see the real things and cannot inspect the quality 
of goods and the authenticity of the description of goods by merchants. Consumers tend to beautify their goods in the process of imagination because of their shopping expectations, and then think that they have bought goods worth more than they have bought, resulting in shopping impulse.

The increasingly prosperous Internet marketing mode, as one of the important marketing methods of merchants, brings huge benefits to merchants, but also inevitably induces more irrational consumption behavior. As long as consumers select good products on the e-commerce page of mobile phones, after clicking on purchase and payment, the selected products will be delivered to consumers through express delivery companies, thus saving the need to go to different shopping malls and buy different products. This kind of fast and convenient shopping at home makes some consumers unable to stop shopping and become addicted to online shopping. The overall level of economic development in cities is far greater than that in rural areas, and the per capita economic level is greater than that in rural areas. Urban college students are more capable of withstanding the economic pressure brought about by online shopping. Therefore, it is not surprising to regard online shopping as a form of entertainment. Consumers generally have anchoring psychology. For the seller, setting a higher price first is easy to form an anchoring price in the buyer's psychology. Bargaining on this basis is much better for the seller. Since online shopping is mostly direct selling and selling goods on a commission basis and there are no middlemen, the price is naturally much cheaper than in offline markets. In addition, online shopping also has a variety of promotional activities, making many consumers covet this small price advantage, resulting in blind and excessive consumption. To a large extent, the consumers who participate in group buying go for the ultra-low price of the products, thus ignoring the quality of the products and the credit of the merchants and blindly consuming impulsively. The organizational framework of e-commerce supply chain management is shown in Figure 1.

In the process of marketing planning and implementation of an enterprise, the capabilities of competitors should be compared, and then the advantages they possess are sought to strengthen this aspect, which can increase consumer confidence in consumption. Consumers not only consume time and trust in the purchase process, but also spend some energy to think about and study the characteristics of the product (You, 2015). Marketing personnel must analyze and study consumers' purchasing psychology when they are doing marketing work, and search for consumers' psychological pain points from words, so that consumers' purchasing behavior will have a certain impact. For the scientific application of consumer planning behavior theory, it is necessary to further clarify the scope of application of consumer planning behavior theory. In the connotation of consumer planning behavior theory, the main service object is rational consumers. That is to say, consumers have clear arrangements and plans for their own consumption behaviors, and will compare certain costs and benefits.

\subsubsection{Negative Emotions and Improper Coping Styles}

Generally speaking, the consumer behavior of users in the mobile Internet environment will be affected at both rational and irrational levels. Consumer's financial situation directly affects mobile Internet users' purchase decisions. Consumers with higher educational level can reasonably consume on the premise of mastering their own financial situation, and will be more cautious about online shopping when it comes to family expenses. With the rapid development of intelligent terminals and mobile Internet, Internet users' online consumption behavior is obviously different from the traditional Internet era. In the enterprise marketing, the marketing behavior always decides whether the goal of the marketing activity is successfully realized and whether the measures established by the marketing purpose are finally implemented. The causes of Internet shopping addiction are similar to and different from those of Internet addiction and shopping addiction. When consumers make irrational consumption, what they pursue is a kind of psychological satisfaction brought about by purchasing the goods. By consuming the goods or services, they can obtain individual satisfaction. Irrational values the power of belief and emotion, believing that there is something that cannot be expressed in words and concepts in the process of human thinking. 
Figure 1. Organizational framework of e-commerce supply chain management

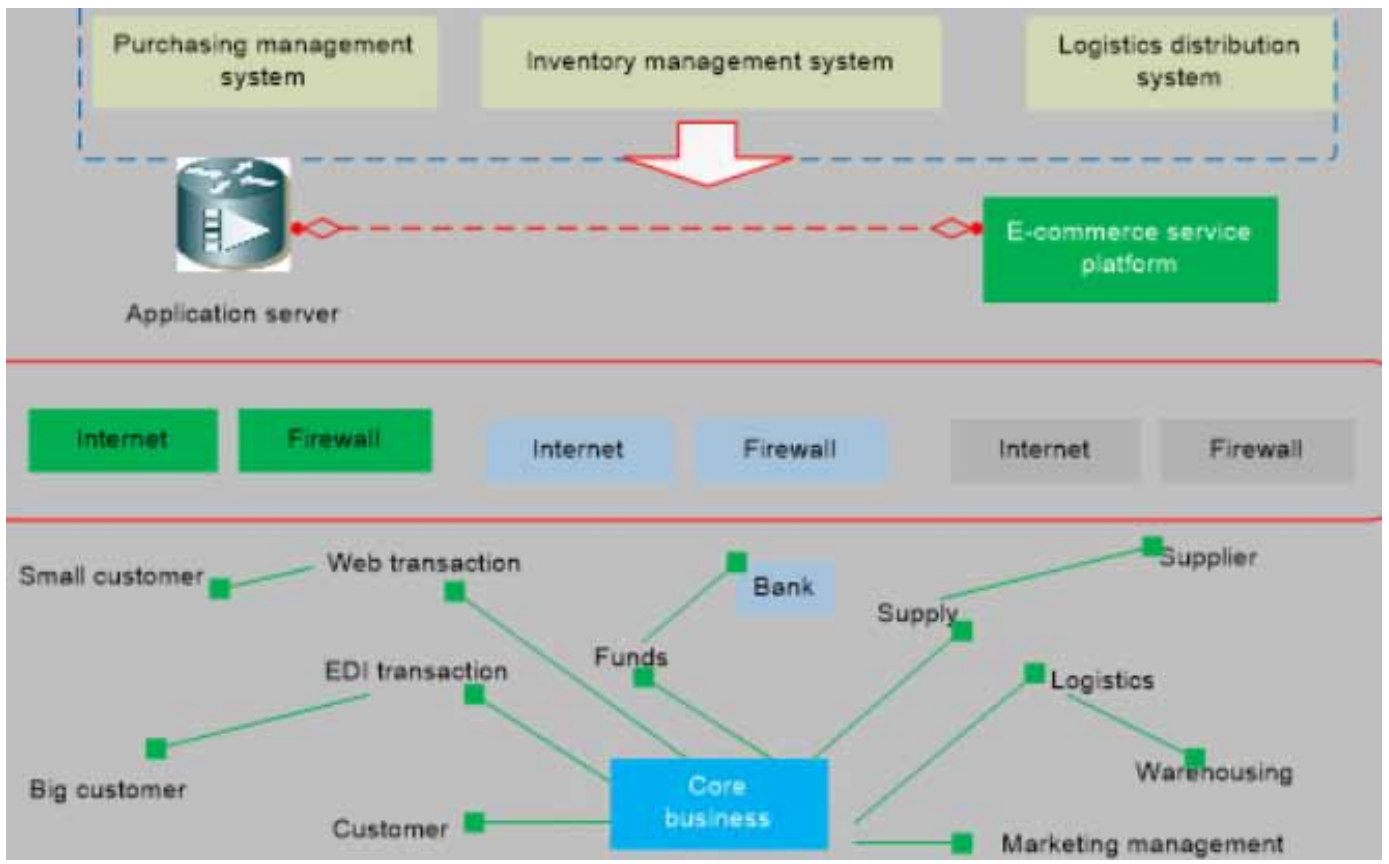

Consumer's decision-making style is essentially a kind of psychological characteristic, and personality traits will fundamentally affect the individual's psychological characteristics, so it can be said that personality traits will also have a certain decisive effect on the psychological characteristics of consumers when they consume behavior. Consumers often do not know enough about the quality and function of products and lack effective information to evaluate the quality of products, so they often behave at a loss when deciding on consumption and place themselves in the weak side. Due to the virtual nature of Internet transactions and the loopholes in the credit evaluation system of thirdparty trading platforms, it is possible to change transaction records and commodity evaluation (Nan, 2014). Many illegal Internet platform operators often adopt the method of creating virtual transaction records, creating the illusion that many people buy goods. From the perspective of emotional theory, impulse buying is the result of emotional response and emotional victory over rationality. If rational consumption is a lower-level consumption that uses economic criteria to make purchase decisions, then irrational consumption is a higher-level consumption.

\subsection{Consumer behavior is affected by mobile Internet marketing}

\subsubsection{The Relationship Between Personality Traits and Online Consumption Decision}

Although social environmental factors and psychological factors of customers are difficult to measure, the behaviors of marketers used to mislead consumers into irrational consumption can be measured under certain conditions. The convenience and effectiveness of shopping websites make up for the deficiency of traditional consumption to a great extent. Consumers can spend anytime and anywhere. The popularity of mobile terminals makes greater use of consumers' fragmented time in online shopping. In order to earn more profits, some marketers often mislead consumers through various means and encourage irrational consumer behavior. In the eyes of businessmen, irrational consumption is most likely to occur and be deliberately cultivated in products and services in emerging markets. If a consumer hesitates before purchasing a product, then the opinions of others will play a decisive 
role in the consumer's purchasing behavior. What kind of consumer behavior and decision-making style each consumer takes are largely determined by their inherent personality traits. Long-term internet access will increase the level of dopamine, a neurotransmitter in the brain, and this chemical substance will make individuals highly excited for a short time. Before shopping, think about whether the commodity is your real need, listen to other people's evaluation of the commodity to prevent impulsive shopping, and regularly count your consumption expenditure.

At the present stage, the study of consumer behavior in cmnet is just starting. It is necessary to improve the relevant theoretical model in combination with the actual situation and to empirically study the main factors that affect users' online shopping. For men, extroverted individuals prefer to use the entertainment function of the network, while introverted users are not very good at using the information function of the network. Shopping decision-making style is basically one aspect of consumer personality. When consumers make purchasing decisions, it affects consumers' purchasing behavior in an implicit way. In other words, shopping decision-making style is essentially an individual's habit and tendency, and is the essential characteristic of consumers' cognition and attitude. Consumers often do not know enough about the quality and function of products and lack effective information to evaluate the quality of products, so they often behave at a loss when deciding on consumption and place themselves in the weak side. Under the Internet environment, different shopping decision-making styles of online shoppers will guide online shoppers to make different online shopping behaviors. Consumers tend to beautify their goods in the process of imagination because of their shopping expectations, and then think that they have bought goods worth more than they have bought, resulting in shopping impulse. Outgoing online shoppers are more in pursuit of perfection and superior quality of goods. They regard online shopping as a form of entertainment and enjoy the process of online shopping. Online shopping tends to select some novel and popular goods. The network architecture of the e-commerce information platform is shown in Figure 2.

Product value plays a decisive role only when there are great differences in the quality of many products in the market, but the current market situation is that the rapid development of science and technology makes the products provided by many manufacturers more and more close in quality and performance. The influence of merchants' marketing strategy on consumers' irrational consumption behavior occupies an important position. Usually, the way of marketing planning can affect the purchasing behavior of consumers, because consumers need to obtain the reasonable price of commodities and their true information through marketers. Consumers have a clear understanding of the composition, cost and practical significance of the products after purchase because they already have a considerable understanding of the products, so that consumers have a large choice space and the market is transparent on the whole. In today's rich material conditions, consumers are no longer satisfied with the practical ease of use of goods, but spend more energy to consider the enjoyment of goods. The popularity of this concept of consumption makes consumers pay more attention to the factors such as interest and appreciation when buying commodities. In some cases, group decisionmaking is more extreme than individual decision-making, that is, groups are often prone to take risks or are extremely conservative. This phenomenon is called extreme transfer. When using the decisionmaking method based on expectation value theory to make judgment, the consumer's risk attitude should be considered, the state in which the consumer is in should be analyzed, and the decision expectation value should be adjusted. Through reasonable theoretical assumptions of consumption behavior, various factors affecting consumption behavior can be simplified.

\subsubsection{Internal Reaction of Consumers' Online Shopping Addiction}

Consumers will feel that in the world of virtual online shopping, they are the center of this virtual world and everything will serve them. In the current enterprise marketing process, many enterprises often only pay attention to their own factors, focusing on the quality of products, ignoring the value trend of consumers. Enjoyment-oriented consumption values are very popular. Online shopping can make people feel happy, satisfied and joyful, while online shopping can also relieve pressure and 


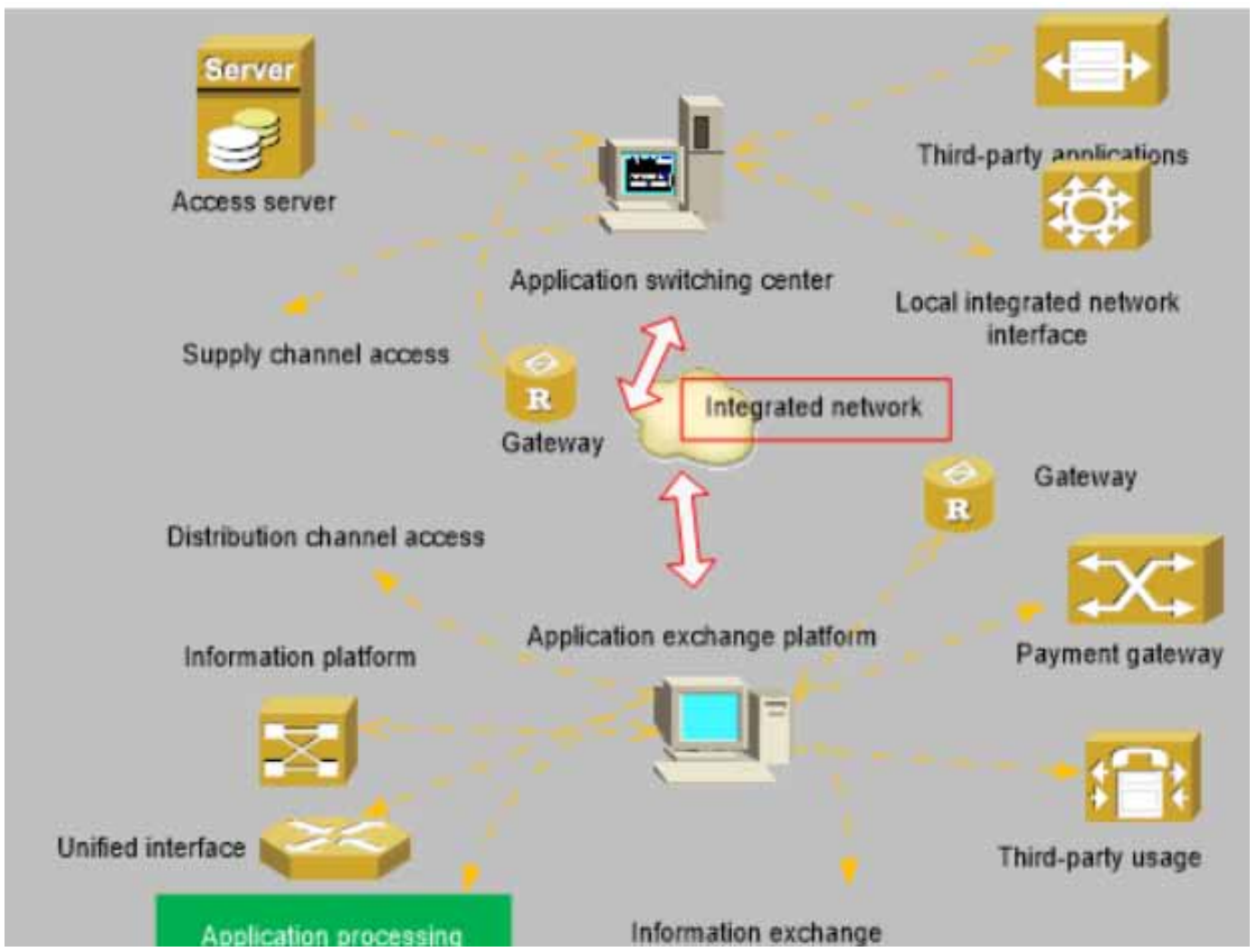

mood. Some websites make people feel personally at the scene by making exquisite pictures and using emotional promotion strategies, coupled with relaxing music. This can play a role in arousing certain emotions and make consumers have the pleasure of sensory enjoyment, social intercourse, bargaining and adventure. The analysis and study of the main causes of consumers' addiction to online shopping are not only aimed at their own addicted consumers, but also to prevent more consumers from becoming addicted. The structure diagram of e-commerce supply chain procurement management and inventory control is shown in Figure 3.

The price competition between a company's products and the average market price can be simply written as follows:

$c_{1}(t)=c_{11}+\left(c_{1 T}-c_{11}\right) \frac{t}{T}$

$c_{2}(t)=c_{21}+\left(c_{2 T}-c_{21}\right) \frac{t}{T}$

Initialize, calculate the connection weight and threshold, and then assign any value:

$I_{i}=\left[\sum_{j=1}^{p} \omega_{j}^{m} y_{i j}^{m}\right]^{1 / m}$ 


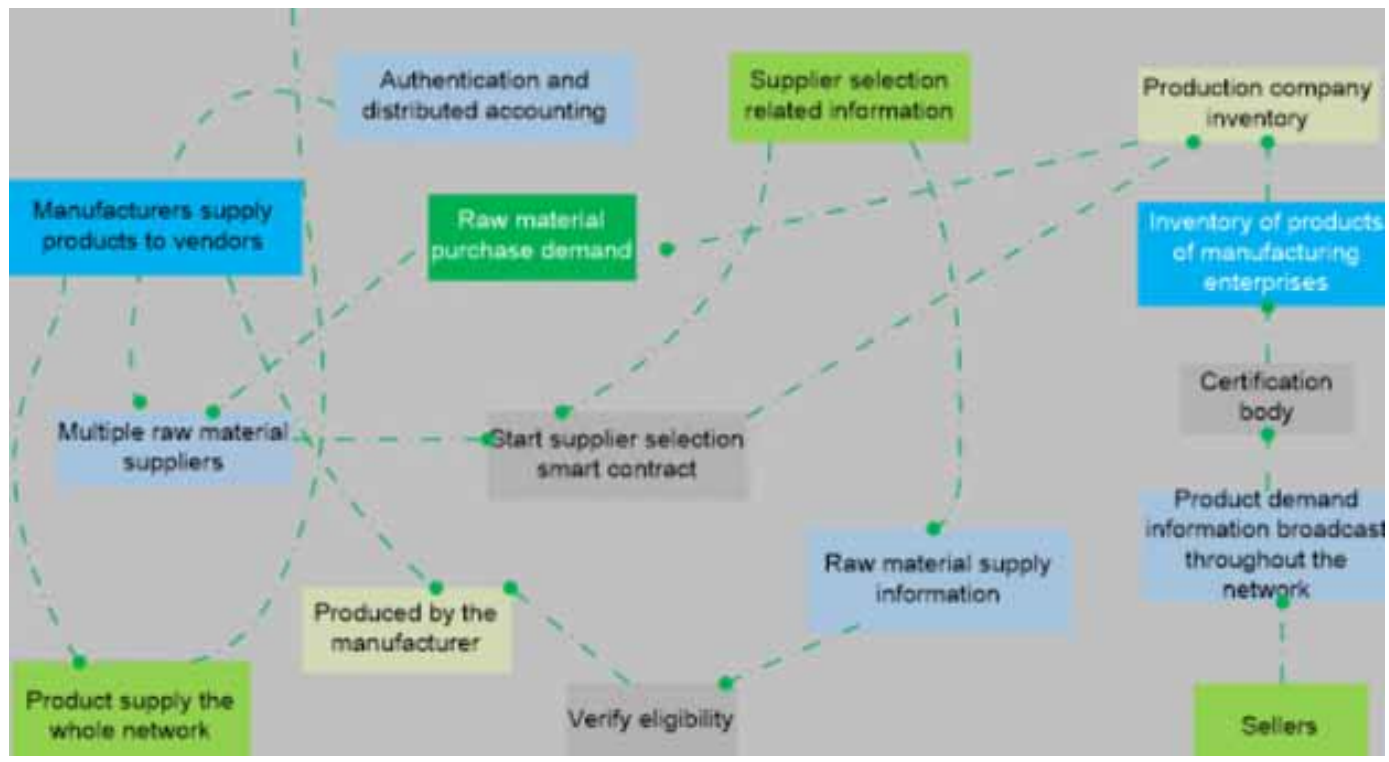

Provide input samples and expected output:

$I_{\omega} \ddot{\delta}=F_{r} d-K_{\omega} \dot{\delta}-C_{\omega} \delta-K_{1} e \delta$

The calculated weight results are shown in Table 1.

With the continuous development of market economy and the change of consumer demand, market refinement oriented by consumer's individual needs has become the inevitable trend of marketing. The shopping website just meets this demand of online shoppers. The colorful online shopping pages and timely communication can make consumers feel happy and have fun in social intercourse. In the enterprise marketing, the marketing behavior always decides whether the goal of the marketing activity is successfully realized and whether the measures established for the marketing purpose are finally implemented (Zheng, 2013). There is no restriction on the business hours of shopping websites, payment is quick, and delivery is delivered to the door by express delivery, which to a large extent achieves the goal that the traditional consumption mode cannot achieve. Many online shoppers are addicted to the pleasure-seeking process in the online shopping process, making individuals consume excessively, causing double losses of time and property, and causing online shopping addiction. For consumers, it is necessary to overcome anchoring decisions on a judgment of short-term trends.

\section{ANALYSIS ON PSYCHOLOGICAL FACTORS OF ONLINE SHOPPING ADDICTION}

\subsection{EEG Characteristics of Online Shopping Addicts}

Every family has its own consumption concept, but due to the different economic conditions and cultural level of the family, the consumption concept of different families also has deviation. Online shopping addiction makes the society develop too fast and the work pressure is very great, which makes people's life more monotonous and boring. Addiction can be divided into mental addiction and process addiction, and can be divided into substance addiction and process addiction according 
Table 1. The intensity of price competition on various impact factors

\begin{tabular}{|l|l|}
\hline Impact factor & Action intensity \\
\hline Security of Online Payment & 0.152 \\
\hline User information security & 0.082 \\
\hline Page style design & 0.076 \\
\hline Page response speed & 0.141 \\
\hline Convenience of communication & 0.068 \\
\hline Integrity of goods received & 0.117 \\
\hline Number of independent visits & 0.248 \\
\hline Personalized service & 0.727 \\
\hline
\end{tabular}

to addiction sources. Different addictions can be studied from the perspectives of biology, medicine and psychology. The brain is a multi-level and open complex giant system. Its advanced functions include various psychological activities such as perception, attention, memory, learning, language, thinking, emotion, consciousness, etc. As long as the brain does not die, it will continuously generate brain waves. Acquaintances are more likely to generate trust, disseminate product information in social networks, and gain more consumer recognition. The physical and psychological quality, selfcontrol ability, intelligence education level and different attitudes towards psychological tests of the subjects will affect the accuracy of psychological tests. The reliability of this test method usually has a certain error rate, and the test method and scoring standard also have certain disputes, even contradictory conclusions.

Under certain conditions, waveforms that do not conform to the rules of brain waves may appear, such as sharp slow composite waves, sharp waves or three-phase waves. Figure 4 is an abnormal EEG when online shopping addicts have consumption conflicts.

In order to eliminate the influence of the different dimensions of the original data, data preprocessing is performed based on data mining. The collected raw data needs to be standardized. The standardized formula is:

$$
n=\sum_{i=1}^{R} P_{l} W_{l, j}+b
$$

Need to meet:

$$
\mathrm{n}=\mathrm{W}^{*} \mathrm{P}+\mathrm{b}
$$

It can be seen from Figure 5 that the amplitude of brain wave fluctuations of online shopping addicts during shopping behavior is very large and completely irregular. Comparing the above electroencephalogram, Figure 5 shows the brainwave signal of a normal adult.

The online shopping environment has multiple advantages such as convenience, speed, variety, low price, and the use of fragmented time compared to the traditional consumer environment. The results of the correlation analysis table of personality traits and online shopping addiction are shown in Table 2.

Pearson correlation analysis was conducted on the five dimensions and total scores of online shopping decision-making methods and the four factors and total scores of online shopping addiction. 




The analysis results of online consumption decision-making style and online shopping addiction are shown in Table 3.

The city has a wide area and a large number of people. City students can get more contact with all kinds of brands in shopping malls and specialty stores. Their preferences are clear and they have higher brand loyalty. Therefore, they are more accustomed to choosing brand products that they are familiar with or like in online shopping. Logically speaking, consumer behavior should be the leader of marketing and complement and deepen marketing. Women are more likely to have pleasant psychology in the process of online shopping, and many women say it is very pleasant to receive express delivery. In other words, women enjoy shopping more than men, including the shopping process and shopping results. In online shopping, consumers will be forced to rush forward to purchase and will also be anxious under the promotion and encouragement of e-commerce. seconds kill means they will soon be bought by others and must rush forward quickly to reach their purchase goal. Women spend more time browsing the shopping interface. They compare product information and prices in many ways until they find the best and cheapest product, which takes more time.

As the initial place for socialization of individuals, the family has a great influence on individuals. If you are educated by your family from an early age, your consumption behavior will be relatively rational. Otherwise, you will be prone to unreasonable consumption behavior, such as online shopping addiction. Electroencephalogram (EEG) is a signal that reflects the change of human consciousness, mental state and psychological effect, and the change of human emotion is instantaneous and sudden. Therefore, EEG signals are also changing from beginning to end. This irregular change is considered to have strong randomness and non-stationarity, and is not easy to analyze. In frequency domain analysis, the most commonly used method is frequency spectrum estimation, which can combine the relationship between the power and frequency of EEG signals and convert the time variation 


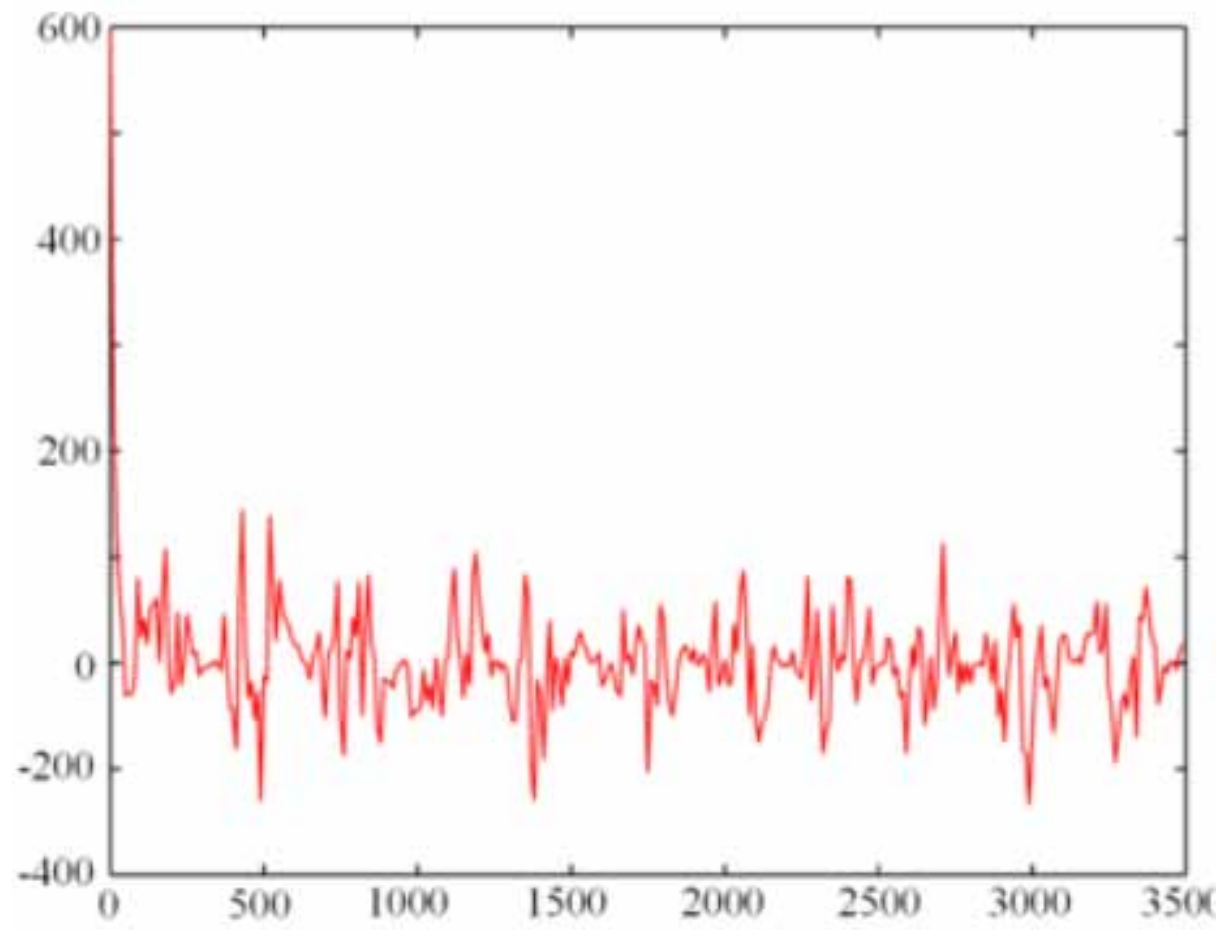

of amplitude into the variation map of EEG power with frequency (Zhang, 2018). It is precisely because of the hedonistic factors in the process of online shopping that individuals are especially easy to indulge in online shopping and cannot extricate themselves. Many online shoppers have a tendency of addiction.

\subsection{Psychological Intervention Strategies for Internet Shopping Addiction}

Internet shopping addicts have a large number of behavioral and impulse control problems, which will bring many negative effects. Netizens should form a good habit of surfing the Internet to prevent their lifestyle from becoming too lazy and too simple and convenient, thus relying too much on the Internet to accelerate the formation of online shopping addiction (Dennis et al., 2020; Yan, 2015).

Table 2. Correlation analysis of personality traits and online shopping addiction

\begin{tabular}{|l|l|l|l|l|l|}
\hline & Functional impairment & $\begin{array}{l}\text { Over } \\
\text { consumption }\end{array}$ & $\begin{array}{l}\text { Withdrawal } \\
\text { reaction }\end{array}$ & $\begin{array}{l}\text { Online } \\
\text { shopping } \\
\text { pleasure }\end{array}$ & $\begin{array}{l}\text { Total score } \\
\text { of online } \\
\text { shopping } \\
\text { addiction }\end{array}$ \\
\hline $\begin{array}{l}\text { Internal and } \\
\text { external tilt }\end{array}$ & .038 & .117 & .024 & .115 & .081 \\
\hline Psychoticism & .064 & -.013 & .028 & -.082 & .011 \\
\hline Nervous & .225 & .210 & .221 & .104 & .221 \\
\hline Camouflage & .062 & .091 & .074 & -.089 & -.081 \\
\hline
\end{tabular}


Table 3. Correlation analysis of online consumption decision-making style and online shopping addiction

\begin{tabular}{|l|l|l|l|l|l|}
\hline & Functional impairment & $\begin{array}{l}\text { Over } \\
\text { consumption }\end{array}$ & $\begin{array}{l}\text { Withdrawal } \\
\text { reaction }\end{array}$ & $\begin{array}{l}\text { Online } \\
\text { shopping } \\
\text { pleasure }\end{array}$ & $\begin{array}{l}\text { Total score } \\
\text { of online } \\
\text { shopping } \\
\text { addiction }\end{array}$ \\
\hline High quality & .031 & .118 & .089 & .256 & .118 \\
\hline Entertainment & .359 & .476 & .381 & .513 & .473 \\
\hline $\begin{array}{l}\text { feeling of } \\
\text { freshness }\end{array}$ & .323 & .395 & .334 & .445 & .415 \\
\hline $\begin{array}{l}\text { Decision } \\
\text { perplexity }\end{array}$ & .281 & .289 & .285 & .262 & .332 \\
\hline Habit & .186 & .292 & .261 & .357 & .285 \\
\hline $\begin{array}{l}\text { Decision total } \\
\text { score }\end{array}$ & .354 & .463 & .391 & .584 & .495 \\
\hline
\end{tabular}

Women's damage to social life such as interpersonal relationships, health and studies caused by online shopping is more obvious (Alemu et al., 2020; San-Martín et al., 2020). Since the reform and opening up, the development of cities has changed with each passing day. The economic development of cities is far faster than that of rural areas. The living standard of urban residents is on average higher than that of rural residents. Compared with urban residents, rural residents are more cautious and thrifty in their consumption. Rational emotive therapy holds that people's emotional disorders are caused by people's irrational beliefs. Treatment is to treat irrationality with rationality, to help patients replace irrational thinking with rational thinking, and to replace irrational belief with reasonable belief, so as to minimize the adverse effects of irrational belief on emotions. In the process of online shopping, the degree of various psychological needs that women hope to satisfy through online shopping is higher than that of men. This may be related to the different social roles of men and women. Women tend to like shopping more than men. Therefore, the idea of online shopping and the psychological needs to be satisfied through online shopping are relatively high.

Individual behavior is often affected by the group, which produces herd effect, that is, when individuals are affected by the group, they will doubt and change their original views and judgments. Online shoppers with high neurotic scores are emotionally unstable, impulsive and prone to impulsive shopping. However, impulse shopping is always accompanied by guilt after purchase, and the satisfaction with the purchased goods is not high. After several impulse purchases, online shoppers with high neurotic scores will have doubts about the goods they choose, and then spend more time on the choice of goods, causing selection problems. Consumer's sex, compulsive personality, negative emotions, low self-esteem level, loneliness, emotional arousal, fantasy, credit card use, values and other factors will all affect consumer's shopping addiction level to varying degrees. These adverse internal and external factors will make consumer's estimation of shopping behavior deviate. Under the condition of limited online shopping behaviors such as the network is not smooth or the bank card balance is insufficient, the abstinence reaction of online shoppers with high neurotic scores is more intense due to the inability to achieve their online shopping wishes and the strong emotional fluctuation, which makes them more likely to feel anxiety, depression and unhappiness. Online shoppers with high neurotic scores have strong habit orientation, like to repeat purchases in their own online stores or have high brand loyalty. This may be because online shoppers with high neurotic scores often have the emotional characteristics of anxiety, worry and nervousness. Familiar shops and commodities will bring them a relaxed shopping experience. Buying in shops or brands that have already been purchased can give them more sense of security. From the perspective of emotional theory, impulse buying is the result of emotional response and emotional victory over rationality. 
Figure 6 . The average reaction time of subjects in the experimental group before going online

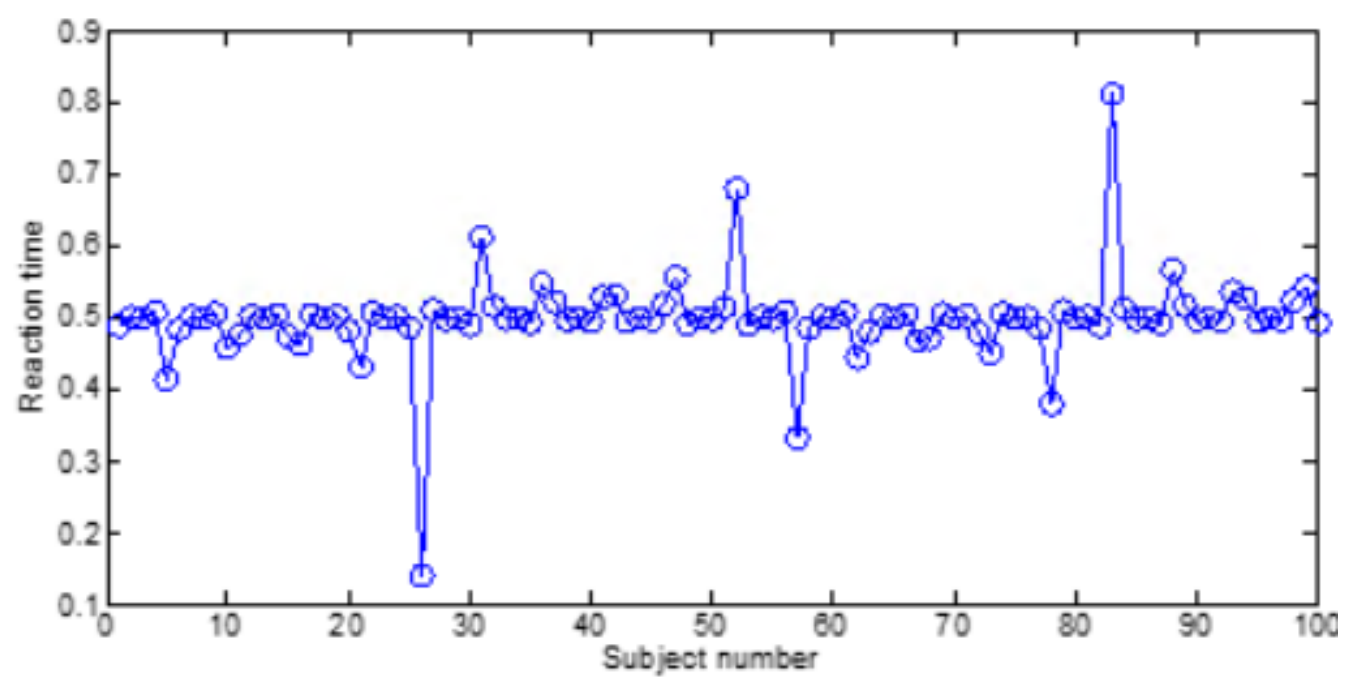

Figure 7. The average response time of control subjects before going online

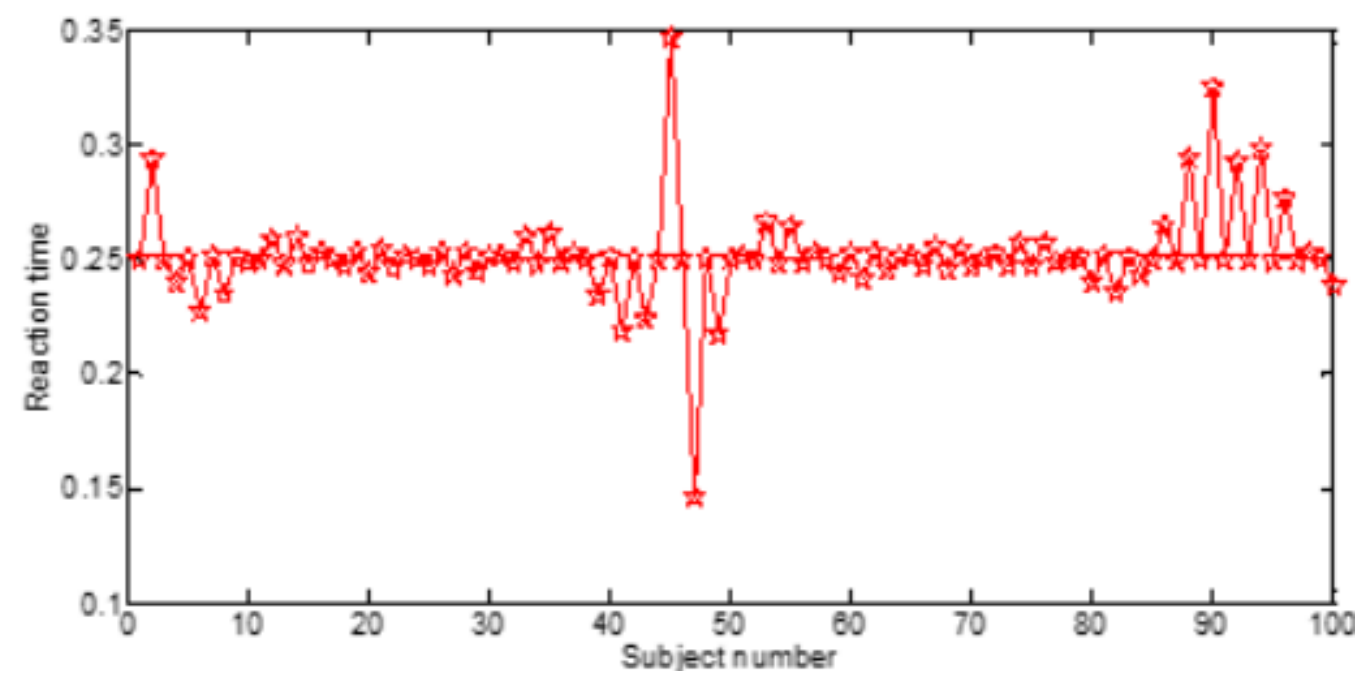


Figure 8. Comparison results of the judgment accuracy rate of subjects in the experimental group before going online

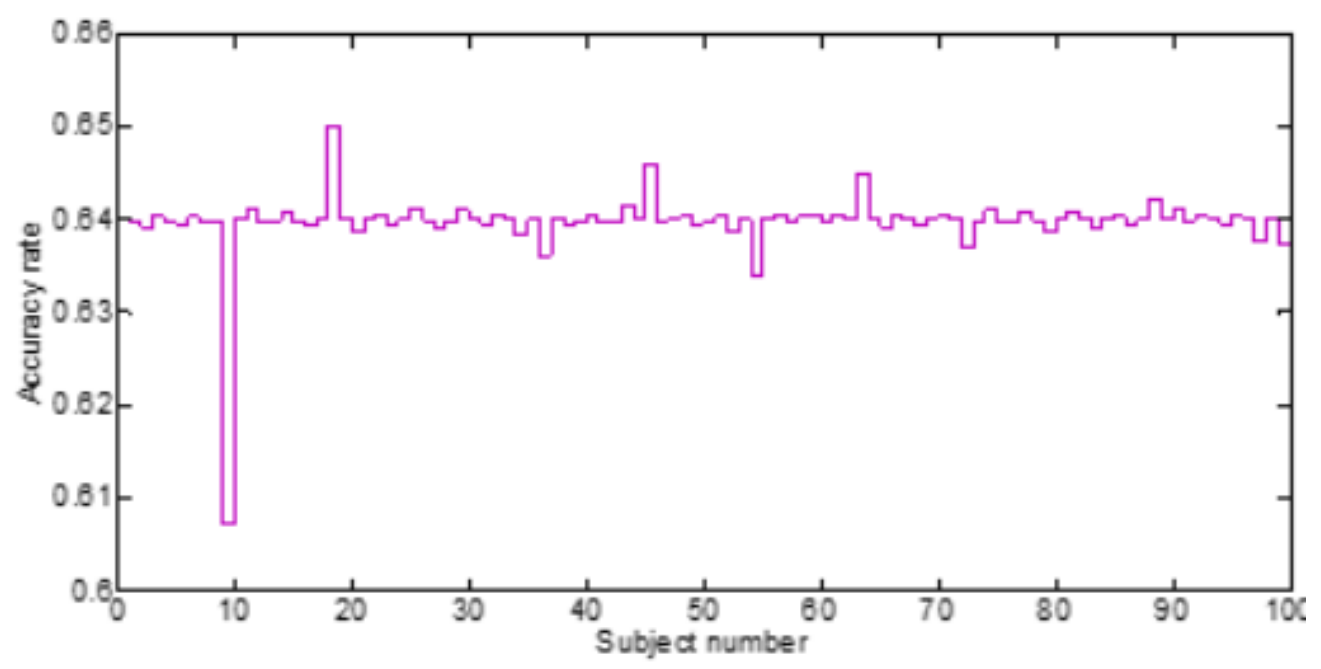

Figure 9. Comparison results of the judgment accuracy rate of the control subjects before going online

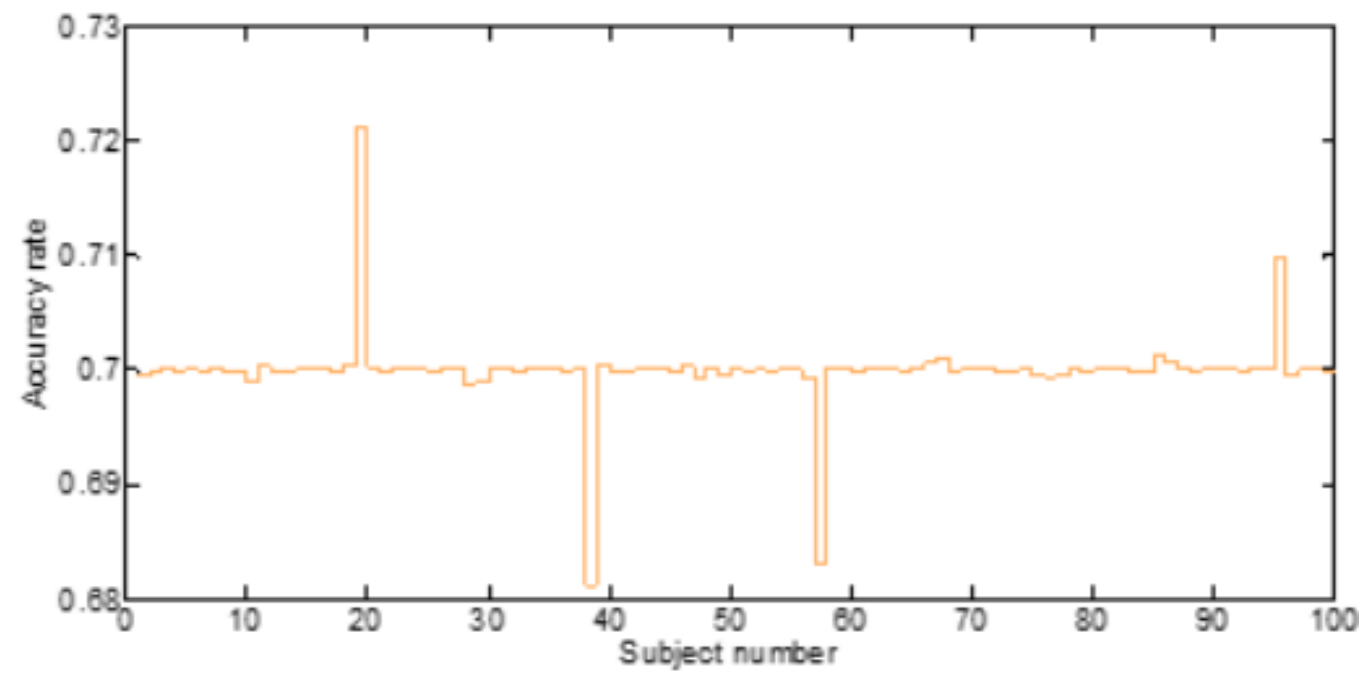


Figure 10. Comparison of the voltages at the electrode positions during the memory judgment of the two groups of subjects during the short-term memory experiment

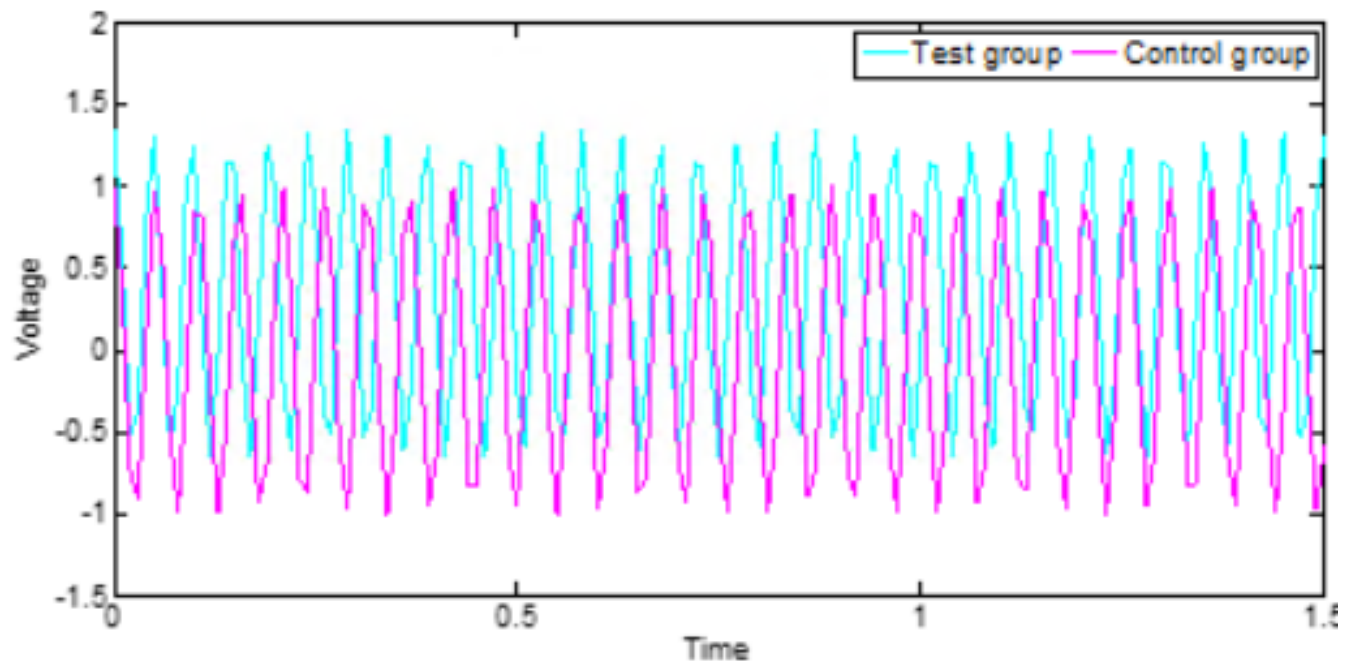

If rational consumption is a lower-level consumption that uses economic criteria to make purchase decisions, then irrational consumption is a higher-level consumption.

People are not always in a rational state when carrying out economic activities, on the contrary, they are often in an irrational state when they need to make rational choices, and this irrational economic behavior has a strong infectious force. The irrational consumption behavior of consumers is caused on one hand by the misleading of consumers in the marketing process, and on the other hand by the irrational and emotional consumption of consumers themselves. Consumers often make irrational decisions when making consumption decisions, resulting in irrational consumption behaviors. Parents of only children will try their best to meet their children's material requirements, so only children enjoy more resources and are financially more affluent. It is difficult to form the habit of thrift. Therefore, when shopping online, the only child enjoys the pleasure of shopping even more and regards shopping as an entertainment way to kill time. Compared with the non-only child, the parents of the only child are more doting on the child, resulting in the only child having more free development space in the process of growth and preferring to pursue novelty and trend. In real life, irrational consumption behaviors such as vulgar consumption, blind consumption and vanity consumption are often manifested due to the influence of consumer psychological factors, misleading marketing methods and insufficient information. Compared with the traditional consumption environment, the online shopping environment has many advantages such as convenience, variety, low price, and utilization of fragmentation time.

Consumer planning behavior theory believes that the subjective evaluation of the people around consumers about products plays a decisive role in what kind of consumption decisions consumers take. When an individual is incomplete with information and must make a decision on a certain consumer behavior, reference opinions from other members of society, especially those with close contacts, play a decisive role. As an online platform, online shopping has a foundation that can satisfy psychological needs, and promotes individual satisfaction and happiness. However, different individuals have different types and degrees of psychological needs than they want to satisfy through online shopping. After careful analysis of the consumer's planned behavior theory, it can be seen that once consumers have the desire to purchase related products of the enterprise, they will immediately pay attention to 
the corresponding products. Online shopping is just a way of shopping. Online shopping only meets some of the individual's needs, but it cannot completely replace all of their needs, such as belonging, self-esteem, and self-realization. These needs also need to be met in real life.

From Figures 6-9, we can see that the average reaction time of the experimental group is slightly longer than that of the control group, while the correct judgment rate of the experimental group is significantly lower than that of the control group. This result suggests that the short-term memory of those who overuse the Internet was significantly lower than that of the normal subjects when the two groups of subjects did not use the Internet. This result shows that excessive use of the Internet has a negative impact on the short-term memory of the subjects.

Patients who overuse the Internet can satisfy their body and mind and become more active through the use of the Internet. This is one of the reasons why Internet users are addicted to the Internet. Figure 10 shows the comparison of the voltage at the electrode position during the memory judgment of the two groups of subjects during the short-term memory experiment.

\section{CONCLUSION}

In order to get rid of the online shopping addiction behaviors, habits and psychological states that affect their health and destroy the happiness of their families, consumers must intervene, prevent and change the online shopping addiction phenomenon from various aspects. Internet shopping addiction is an obsessive-compulsive disorder that requires systematic psychotherapy. Rational emotive therapy holds that people's emotional disorders are caused by people's irrational beliefs. Treatment is to treat irrationality with rationality, to help patients replace irrational thinking with rational thinking, and to replace irrational belief with reasonable belief, so as to minimize the adverse effects of irrational belief on emotions. In the psychological intervention of consumers' online shopping addiction, attention should be paid to the intervention of conspicuous and hedonistic consumption tendencies existing in consumers, so as to guide consumers to overcome the improper idea of regarding consumption as showing off their status and help them establish scientific and healthy consumption values. For consumers, it is necessary to overcome anchoring decisions on a judgment of short-term trends. As for the buyer, he should always be alert to fall into the trap of anchoring prices, distinguish different qualities of different items, and adhere to the principle of meeting his own needs. 


\section{REFERENCES}

Alemu, M. H., Sigurdsson, V., Fagerstrøm, A., \& Foxall, G. R. (2020). Developing the e-commerce sector for the fishery industry: What business are we really in? Managerial and Decision Economics, 41(2), 274-290. doi: $10.1002 /$ mde. 3089

Andrason, A. (2016). From vectors to waves and streams: An alternative approach to semantic maps. Stellenbosch Papers in Lingus, 45, 1-29. doi:10.5774/45-0-211

Arens, A. K., Marsh, H. W., Pekrun, R., Lichtenfeld, S., Murayama, K., \& vom Hofe, R. (2016). Math SelfConcept, Grades, and Achievement Test Scores: Long-Term Reciprocal Effects Across Five Waves and Three Achievement Tracks. Journal of Educational Psychology, 109(5), 621-634. doi:10.1037/edu0000163

Balasubramanian, S. V. (2015). Integrative Medicine System Based On Music. Alternative Therapies in Health and Medicine, 22(S1), 14-23. PMID:27089526

Celeste, R. K., \& Fritzell, J. (2018). Do Socioeconomic Inequalities in Pain, Psychological Distress and Oral Health Increase or Decrease Over the Life Course? Evidence from Sweden over 43 years of follow-up. Journal of Epidemiology and Community Health, 72(2), 160-167. doi:10.1136/jech-2017-209123 PMID:29175868

Darin-Mattsson, A., Andel, R., Celeste, R. K., \& Kåreholt, I. (2018). Linking financial hardship throughout the life-course with psychological distress in old age: Sensitive period, accumulation of risks, and chain of risks hypotheses. Social Science \& Medicine, 201(March), 111-119. doi:10.1016/j.socscimed.2018.02.012 PMID:29471180

Dennis, A. R., Yuan, L., Feng, X., Webb, E., \& Hsieh, C. J. (2020). Digital Nudging: Numeric and Semantic Priming in E-Commerce. Journal of Management Information Systems, 37(1), 39-65. doi:10.1080/07421222 .2019 .1705505

Duff, P. A., Anderson, T., \& Doherty, L. (2015). Media-hype: Self-reinforcing news waves, journalistic standards and the construction of social problems. Global Chinese, 20(8), 508-530.

Min, Z., \& Zhe, Z. (2015). The influence of word-of-mouth on consumers' impulsive purchases under the network environment. Soft Science, (10), 114-118.

Nan, L. (2014). Analysis and countermeasures of online shopping addiction among college students. New Curriculum: Middle, (3), 127-128.

Qian, Y. (2016). Research on Internet Shopping Addiction of Medical Students. Chinese Journal of School Doctor, 30(10), 727-728.

Research on the Impact of Expectation Regret on Consumers' Impulsive Buying Behavior. (n.d.). Modern Business, (20), 19-21.

San-Martín, S., Jimenez, N., Camarero, C., \& San-Jose, R. (2020). The Path between Personality, Self-Efficacy, and Shopping Regarding Games Apps. Journal of Theoretical and Applied Electronic Commerce Research, 15(2), 59-75. doi:10.4067/S0718-18762020000200105

Wang, C., Jun, F., \& Song, Y. (2018). Analysis of the impact of e-commerce shopping festival on consumers 'impulsive buying behavior. Price Theory and Practice, (7), 127-130.

Wang, X., \& Tao, W. (2015). Differences in consumption behavior and structural evolution between urban and rural residents. Quantitative Economics and Technology Research, (10), 90-107.

Wang, Y. (2015). An empirical study of website characteristics on consumers 'impulsive buying behavior. Special Zone Economics, (3), 141-142.

Yan, N. (2015). Research on the Causes, Harm and Intervention Mechanisms of Female Online Shopping Addiction under the Background of Internet. New Campus: Early Issues, (5), 186-187.

You, C. (2015). Analysis of Influencing Factors of College Students' Internet Shopping Addiction. Cooperative Economy and Technology, (11), 102-103.

Zhang, Y. (2018). Research on the Relationship between College Students' Online Shopping Addiction and Academic Delay. Science and Technology Information, 16(27), 255-256. 
Zhao, W., Sa, S., \& Cai, X. (2017). The Effect of Online Promotion Methods on Consumers 'Impulsive Purchase. Chinese Market, (13), 99-101.

Zheng, M. (2013). The formation mechanism and countermeasures of online shopping addiction. Media Watch, (9), 26-28.

YANG Jinke (1982- ), Chinese, male, born in changge City in Henan Province, Doctor of Law, Associate professor of the School of Law in Henan University,Major Research Fields:Criminal Psychology. Email: yangjinke789@126. com Address: School of Law, Henan University, 85 Minglun Street, Shunhe District, Kaifeng City, Henan Province(475001). Mobile: +86 15637845564. 